\title{
Fósforo da biomassa microbiana e atividade de fosfatases ácidas durante a diminuição do fósforo disponível no solo
}

\author{
Luciano Colpo Gatiboni(1), João Kaminski(2), Danilo dos Santos Rheinheimer ${ }^{(2)}$ e Gustavo Brunetto(2)
}

\begin{abstract}
(1)Universidade do Estado de Santa Catarina, Departamento de Solos e Recursos Naturais, Avenida Luis de Camões, no 2.090, CEP 88520-000 Lages, SC. E-mail: gatiboni@udesc.br (2)Universidade Federal de Santa Maria, Departamento de Solos, Campus Universitário, CEP $97105-900$ Santa Maria, RS. E-mail: jk@smail.ufsm.br, danilo@ufsm.br, brunetto.gustavo@gmail.com
\end{abstract}

\begin{abstract}
Resumo - O objetivo deste trabalho foi avaliar o conteúdo de fósforo armazenado na biomassa microbiana e a atividade de fosfatases ácidas, durante a diminuição dos teores de fósforo disponível no solo, causado por cultivos sucessivos com plantas. Foram utilizadas amostras de Latossolo Vermelho distroférrico típico, com adição prévia de fosfatos solúveis $\left(0,180,360,540\right.$ e $720 \mathrm{~kg} \mathrm{ha}^{-1}$ de $\left.\mathrm{P}_{2} \mathrm{O}_{5}\right)$, aplicados em seis anos consecutivos. Efetuaram-se 15 cultivos sucessivos com diferentes plantas, em casa de vegetação, sem a reposição do fósforo absorvido pelas plantas. Após cada três cultivos sucessivos, foram determinados: o teor de fósforo disponível por resina trocadora de ânions, o fósforo microbiano e a atividade de fosfatases ácidas. Com a diminuição da disponibilidade de fósforo do solo, a quantidade de fósforo armazenada na biomassa microbiana do solo diminuiu, e a atividade de fosfatases ácidas aumentou. Em solos com baixo teor de fósforo e de resíduos de plantas, o P microbiano tem pouca importância para a nutrição das plantas.
\end{abstract}

Termos para indexação: biomassa microbiana, formas de fósforo, fósforo lábil, fósforo orgânico.

\section{Soil microbial biomass phosphorus and activity of acid phosphatases during decline of soil available phosphorus}

\begin{abstract}
The objective of this work was to evaluate the content of phosphorus stored in the soil microbial biomass and the activity of acid fosfatases, during the decline of soil available phosphorus, caused by successive crops in pot experiment. Samples of Oxisol were utilized with previous addition of soluble phosphates (0, 180, 360, 540 , and $720 \mathrm{~kg} \mathrm{ha}^{-1}$ of $\mathrm{P}_{2} \mathrm{O}_{5}$ ), applied in six consecutive years. The soil samples were submitted to 15 successive crops in greenhouse, without replacement of absorbed phosphorus by plants. After each three successive crops, soil was sampled, and the following variables were determined: the available phosphorus by anion exchange resin, phosphorus stored in the soil microbial biomass and the activity of acid phosphatases. As a consequence of the reduction of the soil available phosphorus, the amount of microbial phosphorus decreased, and the activity of phosphatases increased. In soils with low phophorus content and no plant residues, the microbial $\mathrm{P}$ has little importance for plant nutrition.
\end{abstract}

Index terms: soil microbial biomass, phosphorus forms, organic phosphorus, labile phosphorus.

\section{Introdução}

O fósforo (P) é encontrado no solo em duas formas principais: inorgânica e orgânica. As formas de $\mathrm{P}$ inorgânico compreendem, principalmente, aquelas adsorvidas aos grupos funcionais dos colóides inorgânicos, por meio de ligações monodentadas, bidentadas e binucleadas (Parfitt, 1978), cuja energia de ligação com os colóides aumenta, nesta e na ordem inversa, a sua labilidade. As formas orgânicas de P (Po) representam os íons fosfatos ligados aos compostos orgânicos, sua labilidade está diretamente relacionada à suscetibilidade de decomposição do radical orgânico ao qual o fosfato está ligado. Assim, os fosfatos diésteres são bastante suscetíveis ao ataque microbiano e compõem o "pool” de P lábil do solo. No entanto, compostos que possuem alta carga residual, como os fosfatos monoésteres, são fortemente adsorvidos aos colóides inorgânicos e permanecem protegidos química e fisicamente do ataque microbiano (Stewart \& Tiessen, 1987).

Quando se utiliza a técnica do fracionamento das formas de $\mathrm{P}$ do solo, tem-se observado que os fertilizantes adicionados ao solo se acumulam principalmente em 
formas inorgânicas (Rheinheimer \& Anghinoni, 2001). Essas, em solos bem adubados ou pouco intemperizados, podem ser a principal fonte de $\mathrm{P}$ às plantas, enquanto em solos com baixos teores de $\mathrm{P}$ disponível, o $\mathrm{P}$ orgânico torna-se relevante para o sistema (Gatiboni et al., 2007; Rheinheimer et al., 2008). De acordo com Tiessen et al. (1984), em solos pouco intemperizados, a contribuição do P orgânico é de $14 \%$ na nutrição das plantas, enquanto nos solos mais velhos pode chegar a $80 \%$. Adicionalmente, Beck \& Sanches (1994) observaram que em solos com adubação fosfatada, a contribuição do P orgânico é de $9 \%$, aumentado para $34 \%$ nos sistemas sem adubação. Da mesma forma, Gatiboni et al. (2005) relatam que, em solos adubados, a contribuição do P orgânico para a nutrição das plantas foi de $6 \%$, e aumentou para $43 \%$ no solo sem adição de fertilizantes minerais.

Assim, quanto mais pobre em $\mathrm{P}$ disponível for o sistema, maior é a dependência das formas orgânicas, inclusive do $\mathrm{P}$ armazenado na biomassa microbiana. Este é um compartimento de $\mathrm{P}$ bastante dinâmico, que absorve e imobiliza $\mathrm{P}$ da solução do solo, quando do aumento da disponibilidade no sistema, mas o libera gradativamente pelo ajustamento da população microbiana ao fornecimento de energia e P no sistema (Conte et al., 2002; Martinazzo et al., 2007). A aquisição do P orgânico pela biomassa microbiana do solo pode se dar por degradação total da matéria orgânica do sistema ou pela mineralização específica do fosfato orgânico, por meio da atuação e exoenzimas do tipo fosfatases (McGill \& Cole, 1981).

O objetivo deste trabalho foi estimar o conteúdo de $\mathrm{P}$ armazenado na biomassa microbiana $\left(\mathrm{P}_{\mathrm{m}}\right)$ e a atividade de fosfatases ácidas, durante a diminuição dos teores de P disponível no solo causado por cultivos sucessivos de plantas.

\section{Material e Métodos}

Para realização deste trabalho, o solo foi coletado em janeiro de 2000, em um experimento com doses de P, instalado em 1994 em Latossolo Vermelho distroférrico típico, conduzido sob sistema plantio direto, em Santo Ângelo, RS ( $\left.28^{\circ} 17^{\prime} 56^{\prime \prime S}, 54^{\circ} 15^{\prime} 46^{\prime \prime} \mathrm{W}\right)$. O solo apresentou os seguintes atributos: argila, $706 \mathrm{~g} \mathrm{~kg}^{-1}$; silte, $223 \mathrm{~g} \mathrm{~kg}^{-1}$; areia, $71 \mathrm{~g} \mathrm{~kg}^{-1}$; Fe extraído por ditionitocitrato-bicarbonato, $129 \mathrm{~g} \mathrm{~kg}^{-1} ; \mathrm{Fe}$ extraído por oxalato de amônio, $70 \mathrm{~g} \mathrm{~kg}^{-1}$; C orgânico total, 17,2 $\mathrm{g} \mathrm{kg}^{-1} ; \mathrm{pH} \mathrm{em}$ água, 4,6; índice SMP, 5,4; Al, 0,85 $\mathrm{cmol}_{\mathrm{c}} \mathrm{kg}^{-1} ; \mathrm{Ca}$,
2,71 $\mathrm{cmol}_{\mathrm{c}} \mathrm{kg}^{-1} ; \mathrm{Mg}$ trocável, $0,96 \mathrm{cmol}_{\mathrm{c}} \mathrm{kg}^{-1} ; \mathrm{K}$ extraído por Mehlich 1, $270 \mathrm{mg} \mathrm{kg}^{-1}$. Foram coletados $15 \mathrm{~kg}$ de solo da camada $0-10 \mathrm{~cm}$, de parcelas que receberam doses anuais de $0,30,60,90$ e $120 \mathrm{~kg} \mathrm{ha}^{-1}$ de $\mathrm{P}_{2} \mathrm{O}_{5}$ por ano, nos totais $0,180,360,540$ e $720 \mathrm{~kg} \mathrm{ha}^{-1}$ de $_{2} \mathrm{O}_{5}$, aplicados até o momento da coleta do solo. Os teores de P extraído por Mehlich 1 foram 8,6, 11,4, 13,3, 21 e $30 \mathrm{mg} \mathrm{kg}^{-1}$, respectivamente, para as referidas doses.

Após a coleta, o solo foi secado ao ar, moído, passado em peneira com malha de $2 \mathrm{~mm}$ e acondicionado em vasos com capacidade de $2 \mathrm{~kg}$. O experimento foi conduzido em casa de vegetação do Departamento de Solos, da Universidade Federal de Santa Maria (UFSM), e as análises foram realizadas no Laboratório de Química e Fertilidade do Solo, no Departamento de Solos da UFSM. O experimento consistiu de 15 cultivos sucessivos com plantas em casa de vegetação, e os tratamentos foram as cinco doses de $\mathrm{P}$ provenientes do experimento em campo. O modelo estatístico utilizado foi um bifatorial em delineamento inteiramente casualizado, em que as doses de $\mathrm{P}$ foi o Fator A, com seis repetições, e as subparcelas no tempo, o Fator B.

As espécies cultivadas, escolhidas em conseqüência das condições climáticas de cada estação do ano, foram: milheto - Pennisetum americanum (L.) Leeke - cultivo 1; aveia-preta - Avena strigosa Schreb cultivos 2, 3 e 4; milho - Zea maiz L. - cultivo 5; soja Glycine max (L.) Merrill - cultivos 6, 7, 8, 9, 13, 14 e 15; crotalária - Crotalaria spectabilis Roth - cultivo 10; e centeio - Secale cereale L. - cultivos 11 e 12. As sementes foram pré-germinadas em laboratório, até a emissão da radícula, e quatro plantas (espécies de rápido crescimento) a 15 plantas (espécies de crescimento lento) foram transplantadas por vaso.

As recomendações da Comissão de Química e Fertilidade do Solo do Rio Grande do Sul e Santa Catarina (2004) foram seguidas e, antes do primeiro e do quinto cultivos, todos os tratamentos receberam a adição de $\mathrm{K}, \mathrm{Ca}, \mathrm{Mg}, \mathrm{S}, \mathrm{Zn}, \mathrm{B}, \mathrm{Cu}$ e Mo. No oitavo cultivo, foi adicionado calcário ao solo, para se manter o pH próximo a 6. Em cada cultivo sucessivo, as plantas foram cultivadas por períodos variáveis de 30 a 45 dias, e o corte foi realizado quando a taxa de crescimento vegetativo das plantas diminuía.

Após cada colheita, o solo foi passado em peneira, secado em estufa e recolocado nos vasos para um novo cultivo. Foram coletadas amostras de solo após cada três cultivos, as quais foram secadas em estufa a $60^{\circ} \mathrm{C}$, moídas, passadas em peneira com malha de $2 \mathrm{~mm}$ e 
armazenadas. Nesse solo, foram analisados: os teores de $\mathrm{P}$ extraído por resina trocadora de ânions em lâminas (Gatiboni, 2003); o P total, por digestão sulfúrica (Kuo, 1996); o P orgânico total, por ignição (Kuo, 1996); o $\mathrm{P}$ inorgânico total (diferença entre $\mathrm{P}$ total e $\mathrm{P}$ orgânico total); e o teor de C orgânico total do solo.

Porções de $50 \mathrm{~g}$ de solo foram submetidas à incubação à temperatura ambiente, às quais foi adicionada água, e o solo foi mantido a $80 \%$ da capacidade de campo por 30 dias. Nessas amostras, foram determinados os teores de $\mathrm{P}$ armazenado na biomassa microbiana, pelo método da fumigação-extração (Brookes et al., 1984), e a atividade de fosfatases ácidas, segundo Tabatabai \& Bremner (1969).

Os resultados foram submetidos à análise de variância e, quando detectados efeitos significativos pelo teste $\mathrm{F}$, a 5\% de probabilidade, foram ajustadas equações de regressão. Testou-se a significância dos componentes linear e quadrático das equações de regressão pelo teste t, tendo sido escolhida a equação significativa com maior grau. O grau de correlacionamento entre os parâmetros foi submetido à análise de correlação de Pearson.

\section{Resultados e Discussão}

Os teores iniciais de $\mathrm{P}$ no solo foram proporcionais à dose de fertilizante fosfatado aplicada (Figura 1). Apenas os tratamentos com adição de 540 e $720 \mathrm{~kg} \mathrm{ha}^{-1}$ de $\mathrm{P}_{2} \mathrm{O}_{5}$ tiveram teores de $\mathrm{P}$ adequados para as culturas, conforme a Comissão de Química e Fertilidade do Solo do Rio Grande do Sul e Santa Catarina (2004), cujo nível crítico às plantas, estimado por resina trocadora de ânions em lâminas, é de $20 \mathrm{mg} \mathrm{kg}^{-1}$.

No decorrer dos cultivos, os teores de P disponível, em todos os tratamentos, diminuíram paulatinamente, em conseqüência da absorção de P pelas plantas (Figura 1). Ao final dos cultivos, foram detectados, no solo, teores de P disponível em torno de 57, 53, 46, 49 e 41\%, em relação aos teores iniciais dos tratamentos $0,180,360$, 540 e $720 \mathrm{~kg} \mathrm{ha}^{-1}$ de $\mathrm{P}_{2} \mathrm{O}_{5}$, respectivamente. Isso indica que as plantas têm capacidade limitada de absorver o $\mathrm{P}$ detectado por resina trocadora de ânions, em solos com baixos teores, pois os teores não decrescem à mesma proporção que nos solos mais adubados. Isto pode ocorrer porque quando os teores de $\mathrm{P}$ disponível atingem níveis muito baixos, o suprimento para as plantas começa a ser mantido também por formas de menor labilidade e pela mineralização do P orgânico, como observado por Tiessen et al. (1984), Beck \& Sanches (1994) e Gatiboni et al. $(2005,2007)$.
A operação de separação das raízes, realizada após cada cultivo e que envolveu o tamizamento e a secagem do solo em estufa, poderia ter provocado a aceleração da decomposição da matéria orgânica, e ter disponibilizado o P orgânico para as plantas. Os resultados apresentados na Figura 2 mostram que ocorreu a decomposição de C orgânico, durante os cultivos sucessivos, e que não houve diferença entre as doses de $\mathrm{P}$ aplicadas. Porém, a mineralização do P orgânico, durante os cultivos, somente

(A)

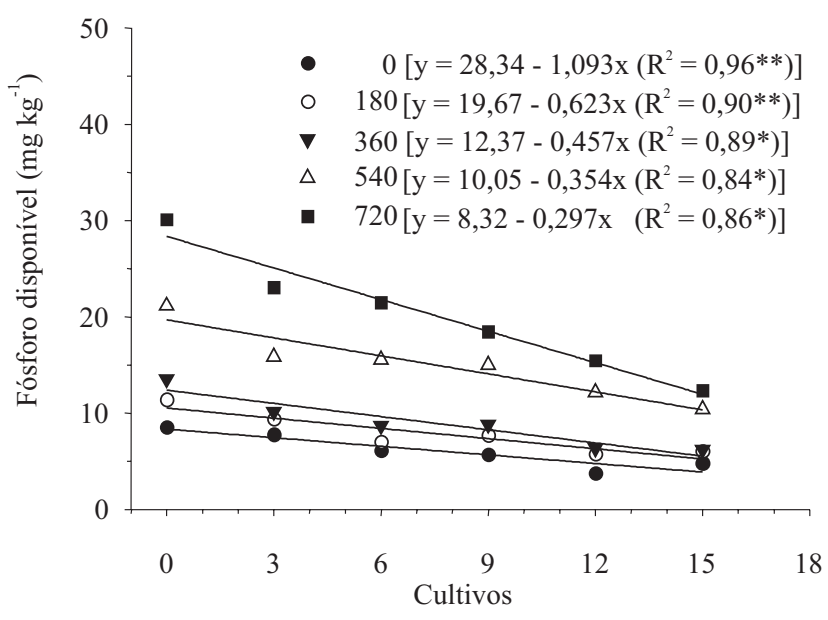

(B)

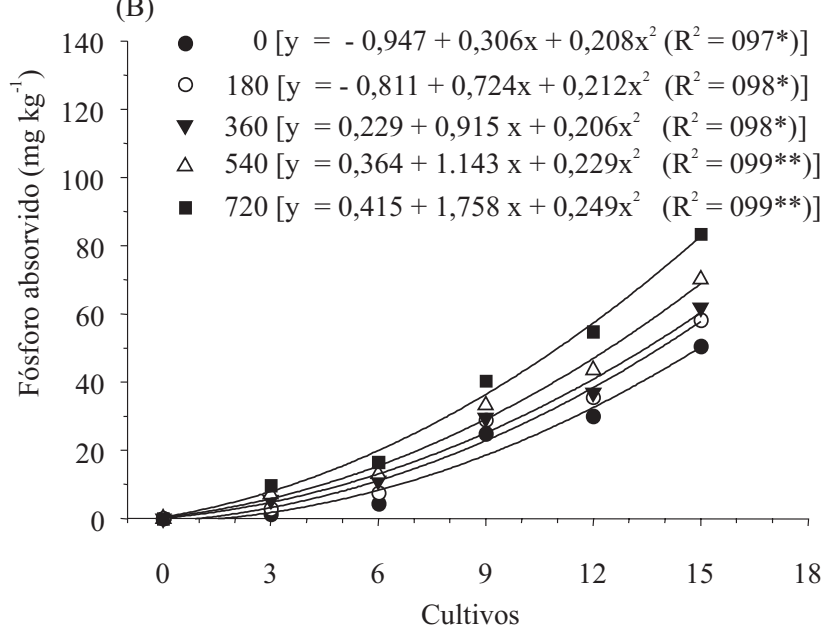

Figura 1. Teores de fósforo disponível por resina trocadora de ânions (A) e teores acumulados de fósforo absorvido pelas plantas (B), em Latossolo Vermelho distroférrico típico, com fertilizante fosfatado em doses de 0 a $720 \mathrm{~kg} \mathrm{ha}^{-1}$ de $\mathrm{P}_{2} \mathrm{O}_{5}$, submetido a 15 cultivos sucessivos em casa de vegetação, sem reposição do fósforo absorvido. * e **Significativo a 5 e $1 \%$ de probabilidade, respectivamente. 
foi significativa para os tratamentos 0 e $180 \mathrm{~kg} \mathrm{ha}^{-1} \mathrm{de}$ $\mathrm{P}_{2} \mathrm{O}_{5}$ (Figura $2 \mathrm{~B}$ ), o que confirma que o uso de formas orgânicas de $\mathrm{P}$, como fonte de $\mathrm{P}$ para as plantas, somente ocorre em sistemas com baixa disponibilidade de fosfato inorgânico. Gatiboni et al. (2005) realizaram análise de ressonância magnética nuclear de ${ }^{31} \mathrm{P}$, nos solos do presente experimento, e observaram que, no solo sem adição de fosfato, ocorreu a mineralização tanto de fosfatos orgânicos de maior labilidade (fosfatos diéster),

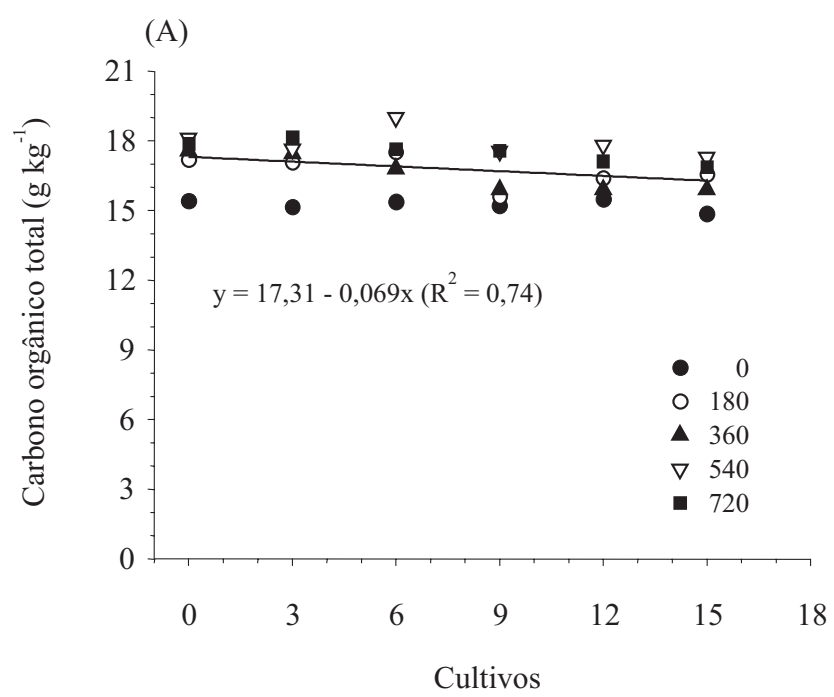

(B)

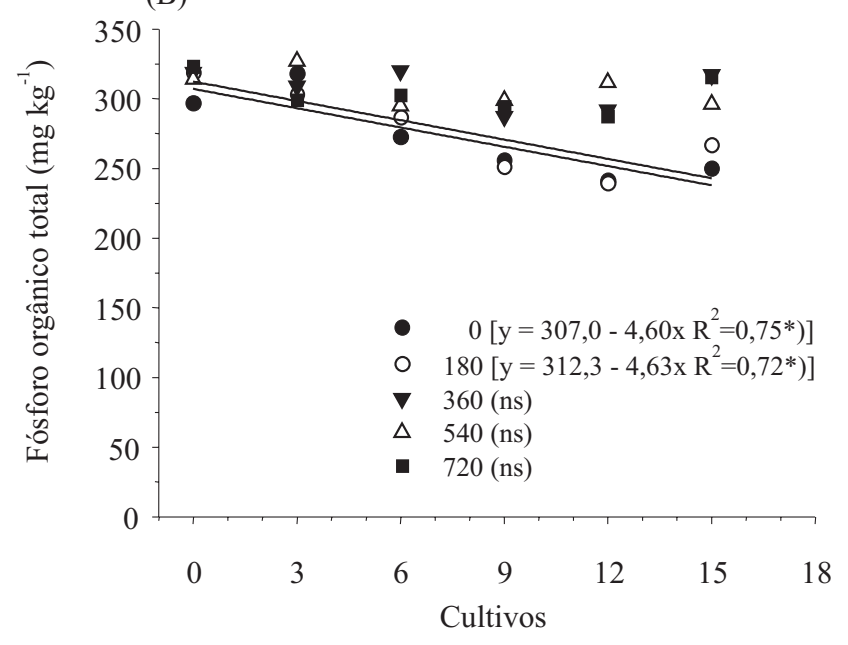

Figura 2. Carbono orgânico total (A) e fósforo orgânico total (B), em Latossolo Vermelho distroférrico típico, com fertilizante fosfatado em doses de 0 a $720 \mathrm{~kg} \mathrm{ha}^{-1}$ de $\mathrm{P}_{2} \mathrm{O}_{5}$, submetido a 15 cultivos sucessivos em casa de vegetação, sem reposição do fósforo absorvido. ns Não-significativo. * Significativo a $5 \%$ de probabilidade. quanto de fosfatos orgânicos de alta recalcitrância (fosfatos monoéster).

Os teores de $\mathrm{P}$ microbiano no solo, antes dos cultivos, eram em torno de $9 \mathrm{mg} \mathrm{kg}^{-1}$, com pouca variação entre as doses de fertilizantes fosfatados adicionados (Figura 3). Valores semelhantes foram encontrados por Conte et al. (2002), para amostras de solos coletadas no mesmo experimento, em que observaram que o $\mathrm{P}$ contido na biomassa microbiana não foi influenciado pelo $P$ oriundo de aplicações de fosfatos, nos anos anteriores à data da coleta. Rheinheimer et al. (2000) usaram amostras de solo, coletadas num experimento adjacente ao utilizado no presente trabalho, e encontraram valores de $\mathrm{P}_{\mathrm{m}}$ que variaram de 29 a $60 \mathrm{mg} \mathrm{dm}^{-3}$, conforme a camada de solo amostrada numa rotação de culturas sob sistema plantio direto. Esses valores são 3 a 6 vezes maiores do que os mostrados na Figura 3, e resultaram da alta disponibilidade de $\mathrm{P}$ naquele solo, que chegava a $95 \mathrm{mg} \mathrm{dm}^{-3}$, enquanto as do presente experimento variaram de 8 a $30 \mathrm{mg} \mathrm{kg}^{-1}$.

Após a realização de três cultivos sucessivos, que causaram diminuição média de $20 \%$ nos teores de $\mathrm{P}$ disponível (Figura 1), a quantidade de P microbiano diminuiu drasticamente nos solos, exceto no tratamento

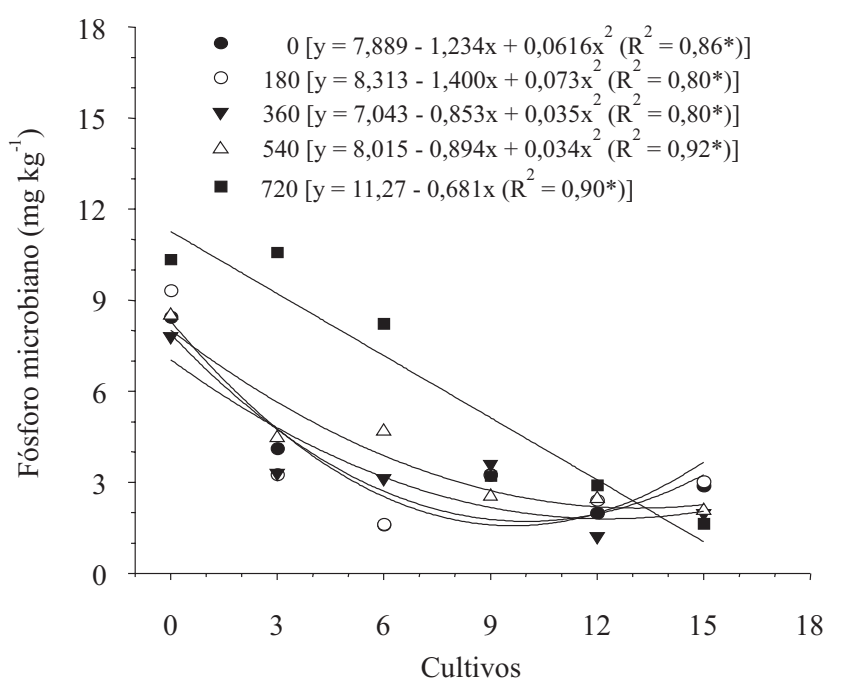

Figura 3. Teores de fósforo armazenado na biomassa microbiana, em Latossolo Vermelho distroférrico típico, com fertilizante fosfatado em doses de 0 a $720 \mathrm{~kg} \mathrm{ha}^{-1}$ de $\mathrm{P}_{2} \mathrm{O}_{5}$, submetido a 15 cultivos sucessivos em casa de vegetação, sem reposição do fósforo absorvido. *Significativo a 5\% de probabilidade. 
com a maior dose de P. Após a realização de seis cultivos sucessivos, essa mesma tendência se manteve, pois somente o tratamento que havia recebido $720 \mathrm{~kg} \mathrm{ha}^{-1} \mathrm{de}$ $\mathrm{P}_{2} \mathrm{O}_{5}$ manteve os teores de $\mathrm{P}$ disponível por resina acima do teor crítico $\left(20 \mathrm{mg} \mathrm{kg}^{-1}\right)$. Isso indica que a adequada disponibilidade de $\mathrm{P}$ às plantas também significa maior disponibilidade para a biomassa microbiana do solo. A partir do nono cultivo, em decorrência do esgotamento do P disponível, os teores de P microbiano foram semelhantes em todos os tratamentos e atingiram patamar médio de apenas $2,3 \mathrm{mg} \mathrm{kg}^{-1}$. Martinazzo et al. (2007) constataram, em Latossolo cultivado sob sistema plantio direto, que a imobilização do $\mathrm{P}$ pela biomassa microbiana do solo é temporária, diminui ao longo do desenvolvimento das culturas e sua variação temporal não é acompanhada por variações no $\mathrm{P}$ extraído pela resina trocadora de ânions.

Assim, em condições de baixa disponibilidade de $\mathrm{P}$ e, principalmente, baixa deposição de resíduos vegetais no solo, a biomassa microbiana é um compartimento que retém pouco $\mathrm{P}$ do solo, com pouca influência sobre a disponibilidade de $\mathrm{P}$ às plantas e pode, inclusive, competir com estas pelo pouco P disponível na solução do solo. Considerando-se que a taxa de renovação anual da biomassa microbiana seja de 40\% (Brookes et al., 1984), o fluxo anual de P, após 15 cultivos sucessivos, seria de apenas $0,9 \mathrm{mg} \mathrm{kg}^{-1}$ por ano e, nesta estimativa, deve-se considerar, ainda, que parte desse P é transferida para as novas gerações de microrganismos e não é, portanto, disponibilizada no sistema.

Quando estudos sobre o P microbiano são feitos em solos bem manejados, com alta deposição de resíduos vegetais, tem-se constatado que este tipo de $\mathrm{P}$ é um compartimento importante no solo, quando da adição de fosfatos solúveis ao sistema, pois ele atua como retardador da adsorção de P, imobilizando-o temporariamente, e é depois mineralizado paulatinamente, com maiores possibilidades de sincronismo com a marcha de absorção das plantas (Rheinheimer et al., 2000, 2008; Conte et al., 2002; Carneiro et al., 2004; Martinazzo et al., 2007).

No presente estudo, em solos com baixos teores de $\mathrm{P}$ disponível, a biomassa microbiana não tem capacidade de imobilizar grandes quantidades de $\mathrm{P}$ e tem menor interferência sobre a disponibilidade de P para as plantas.

A atividade de fosfatases ácidas aumentou com o decorrer dos cultivos e mostrou que aumentou a avidez por $\mathrm{P}$, pelos organismos extrusores de fosfatases (biomassa microbiana e plantas), com a diminuição da disponibilidade de P, conforme relatado também por Olander \& Vitousek (2000), porém não foi observada diferença entre as doses de P utilizadas (Figura 4). Parecem ter ocorrido dois momentos principais: o primeiro, com atividade mais baixa, se manteve até após o sexto cultivo sucessivo; e o segundo, a partir do nono cultivo, em que a atividade de fosfatases ácidas aumentou em todos os tratamentos (Figura 4).

Raghothama \& Karthikeyan (2005) enfatizam que a extrusão de fosfatases por raízes de plantas é um processo resultante da expressão gênica, desencadeada pela diminuição da disponibilidade de $\mathrm{P}$ do solo. Elevada atividade de fosfatases ácidas tem sido medida em solos sob mata nativa, por apresentar alta disponibilidade de carbono orgânico de fácil decomposição, grande quantidade de $\mathrm{P}$ orgânico e de $\mathrm{P}$ contido na biomassa microbiana, e baixíssima disponibilidade de $\mathrm{P}$ (Conte et al., 2002). Assim, alta atividade de fosfatases ácidas passa a ter grande importância em sistemas naturais. No entanto, em agroecossistemas com baixo uso de fertilizantes fosfatados, a alta atividade enzimática não é suficiente para atender à demanda por $\mathrm{P}$ das principais plantas cultivadas comercialmente.

À exceção do P orgânico total, todos os demais parâmetros testados se correlacionaram significativamente $(\mathrm{p}<0,01)$ com o teor total de $\mathrm{P}$ inorgânico do solo (PiT) (Tabela 1). Houve correlações positivas entre o PiT e o P disponível por resina trocadora de ânions $\left(\mathrm{P}_{\mathrm{RTA}}\right)$, $\mathrm{P}$ armazenado na biomassa microbiana e $\mathrm{C}$ orgânico

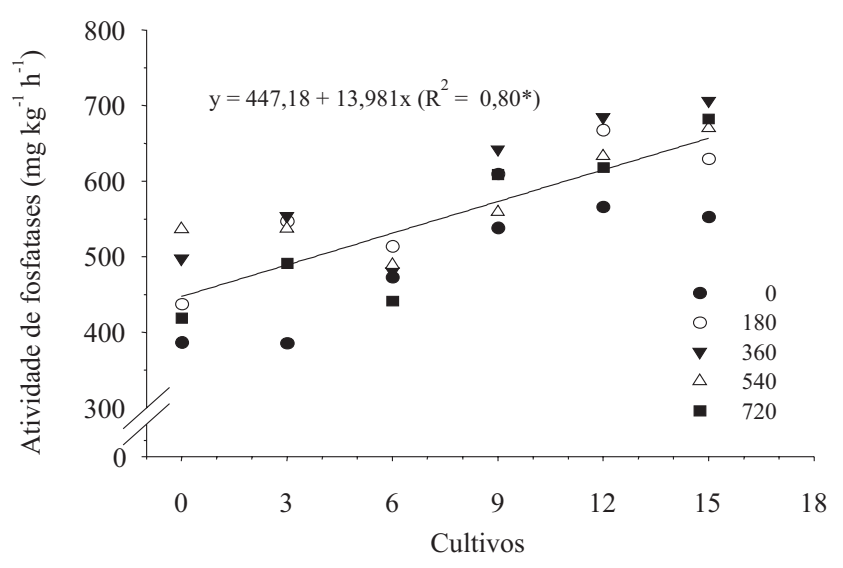

Figura 4. Atividade de fosfatases ácidas, em Latossolo Vermelho distroférrico típico, com fertilizante fosfatado em doses de 0 a $720 \mathrm{~kg} \mathrm{ha}^{-1}$ de $\mathrm{P}_{2} \mathrm{O}_{5}$, submetido a 15 cultivos sucessivos em casa de vegetação, sem reposição do fósforo absorvido. *Significativo a $5 \%$ de probabilidade. 
total (COT). Houve correlação negativa entre o PiT e a atividade de fosfatases ácidas $(-0,718)$, o que indica que a atividade de fosfatases aumenta com o decréscimo do teor de P inorgânico do solo. Alta correlação foi observada entre a atividade de fosfatases e o P absorvido, o que confirma que, neste experimento, a atividade de fosfatases aumentou, ao mesmo tempo em que as plantas extraíam o P do solo. A atividade dessas fosfatases apresentou correlação significativa, também, com o $\mathrm{P}$ microbiano, o que mostra que este é um mecanismo utilizado pelos organismos, quando a biomassa necessita absorver P. No entanto, a atividade de fosfatases não se correlacionou significativamente $(\mathrm{p}>0,05)$ com o PoT, $o$ $\mathrm{P}_{\mathrm{RTA}}$ e o COT, o que mostra que este mecanismo é função direta dos organismos, contrariamente ao observado por Trasar-Cepeda \& Gil-Sotres (1987).

OParmazenado nabiomassa microbiana correlacionouse significativamente $(p<0,01)$ com os compartimentos inorgânicos de $\mathrm{P}$ estudados (PiT e $\mathrm{P}_{\mathrm{RTA}}$ ) e, com menor grau de correlação e menor nível de significância $(\mathrm{p}<0,05)$, com os componentes da matéria orgânica (PoT e COT). Isto indica que a biomassa microbiana foi dependente, principalmente, dos teores de P disponível no solo, conforme observado na Figura 3.

Os parâmetros $\mathrm{P}$ microbiano e atividade de fosfatases ácidas são sensíveis ao decréscimo da disponibilidade de $\mathrm{P}$ do solo, que causa diminuição do P microbiano e aumento da atividade dessas fosfatases. Os valores de $\mathrm{P}_{\mathrm{m}}$ atingem quantidades muito baixas, quando o solo é cultivado intensamente, sem adição de fertilizantes

Tabela 1. Coeficientes de correlação simples de Pearson entre os principais parâmetros relacionados à disponibilidade de fósforo, em Latossolo Vermelho distroférrico típico, com fertilizante fosfatado em doses de 0 a $720 \mathrm{~kg} \mathrm{ha}^{-1}$ de $\mathrm{P}_{2} \mathrm{O}_{5}$, submetido a 15 cultivos sucessivos em casa de vegetação, sem reposição do fósforo absorvido ${ }^{(1)}$.

\begin{tabular}{lcccccr}
\hline Parâmetro & P-abs & PiT & PoT & P RTA $_{\text {RT }}$ & Pm & P-ase \\
\hline PiT & $-0,525^{* *}$ & & & & & \\
PoT & $-0,262^{\text {ns }}$ & $0,340^{\text {ns }}$ & & & & \\
P $_{\text {RTA }}$ & $-0,133^{\text {ns }}$ & $0,628^{* *}$ & $0,533^{* *}$ & & & \\
Pm & $-0,434^{*}$ & $0,737^{* *}$ & $0,401^{*}$ & $0,695^{* *}$ & & \\
P-ase & $0,610^{* *}$ & $-0,718^{* *}$ & $-0,282^{\text {ns }}$ & $-0,319^{\text {ns }}$ & $-0,652^{* *}$ & \\
CoT & $-0,139^{\text {ns }}$ & $0,563^{* *}$ & $0,508^{* *}$ & $0,740^{* *}$ & $0,401^{*}$ & $-0,112^{\text {ns }}$ \\
\hline
\end{tabular}

(1)P-abs: fósforo absorvido pelas plantas; PiT: fósforo inorgânico total; PoT: fósforo orgânico total; $\mathrm{P}_{\mathrm{RTA}}$ : fósforo disponível por resina trocadora de ânions; $\mathrm{P}_{\mathrm{m}}$ : fósforo armazenado na biomassa microbiana; $\mathrm{P}$-ase: atividade

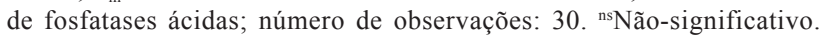
$*$ e **Significativo a 5 e $1 \%$ de probabilidade, respectivamente. fosfatados e com retirada da palhada. Com isso, há pouca possibilidade de contribuição desta forma de $\mathrm{P}$ para a nutrição das plantas e, ainda, no momento da adição de adubos fosfatados, provavelmente, a biomassa microbiana será, juntamente com os sítios de adsorção, um intenso competidor pelo fosfato da solução.

\section{Conclusões}

1. Com a diminuição da disponibilidade de fósforo do solo, a quantidade de fósforo armazenada na biomassa microbiana do solo diminui, e a atividade de fosfatases ácidas aumenta.

2. Em solos com baixo teor de fósforo e de resíduos de plantas, o fósforo microbiano tem pouca importância para a nutrição das plantas.

\section{Agradecimentos}

Ao Conselho Nacional de Desenvolvimento Científico e Tecnológico, pelas bolsas concedidas.

\section{Referências}

BECK, M.A.; SANCHES, P.A. Soil phosphorus fraction dynamics during 18 years of cultivation on a Typic Paleudult. Soil Science, v.34, p.1424-1431, 1994.

BROOKES, P.C.; POWLSON, D.S.; JENKINSON, D.S. Phosphorus in the soil microbial biomass. Soil Biology and Biochemistry, v.16, p.169-175, 1984.

CARNEIRO, R.G.; MENDES, I.C.; LOVATO, P.E.; CARVALHO, A.M.; VIVALDI, L.J. Indicadores biológicos associados ao ciclo do fósforo em solos de Cerrado sob plantio direto e plantio convencional. Pesquisa Agropecuária Brasileira, v.39, p.661-669, 2004.

COMISSÃO DE QUÍMICA E FERTILIDADE DO SOLO DO RIO GRANDE DO SUL E SANTA CATARINA. Manual de recomendação de adubação e de calagem para os estados do Rio Grande do Sul e Santa Catarina. 10.ed. Porto Alegre: SBCS, 2004. 400p.

CONTE, E.; ANGHINONI, I.; RHEINHEIMER, D.S. Fósforo da biomassa microbiana e atividade de fosfatase ácida após aplicação de fosfato em solo no sistema plantio direto. Revista Brasileira de Ciência do Solo, v.26, p.925-930, 2002.

GATIBONI, L.C. Disponibilidade de formas de fósforo do solo às plantas. 2003. 231p. Tese (Doutorado) - Universidade Federal de Santa Maria, Santa Maria.

GATIBONI, L.C.; KAMINSKI, J.; RHEINHEIMER, D.S.; FLORES, J.P.C. Biodisponibilidade de formas de fósforo acumuladas em solo sob sistema plantio direto. Revista Brasileira de Ciência do Solo, v.31, p.691-699, 2007. 
GATIBONI, L.C.; RHEINHEIMER, D.S.; FLORES, A.F.C.; ANGHINONI, I.; KAMINSKI, J.; LIMA, M.A.S. Phosphorus forms and availability assessed by ${ }^{31} \mathrm{P}-\mathrm{NMR}$ in successively cropped soil. Communications in Soil Science and Plant Analysis, v.36, p.2625-2640, 2005.

KUO, S. Phosphorus. In: SPARKS, D.L. (Ed.). Methods of soil analysis: part 3: chemical methods. Madison: SSSA, 1996. p.869-920.

MARTINAZZO, R.; RHEINHEIMER, D.S.; GATIBONI, L.C.; BRUNETTO, G.; KAMINSKI, J. Fósforo microbiano do solo sob sistema plantio direto em resposta à adição de fosfato solúvel. Revista Brasileira de Ciência do Solo, v.31, p.563-570, 2007.

McGILL, W.B.; COLE, C.V. Comparative aspects of cycling of organic C, N, S and P through soil organic matter. Geoderma, v.26, p.267-286, 1981.

OLANDER, L.P.; VITOUSEK, P.M. Regulation of soil phosphatase and chitinase activity by $\mathrm{N}$ and $\mathrm{P}$ availability. Biogeochemistry, v.49, p.175-191, 2000.

PARFITT, R.L. Anion adsorption by soils and soil materials. Advances in Agronomy, v.30, p.1-46, 1978.

RAGHOTHAMA, K.G.; KARTHIKEYAN, A.S. Phosphate acquisition. Plant and Soil, v.274, p.37-49, 2005.
RHEINHEIMER, D.S.; ANGHINONI, I. Distribuição do fósforo inorgânico em sistemas de manejo de solo. Pesquisa Agropecuária Brasileira, v.36, p.151-160, 2001.

RHEINHEIMER, D.S.; ANGHINONI, I.; CONTE, E. Fósforo da biomassa microbiana em solos sob diferentes sistemas de manejo. Revista Brasileira de Ciência do Solo, v.24, p.589-597, 2000.

RHEINHEIMER, D.S.; GATIBONI, L.C.; KAMINSKI, J. Fatores que afetam a disponibilidade do fósforo e o manejo da adubação fosfatada em solos sob sistema plantio direto. Ciência Rural, v.38, p.576-586, 2008.

STEWART, J.W.B.; TIESSEN, H. Dynamics of soil organic phosphorus. Biogeochemistry, v.4, p.41-60, 1987.

TABATABAI, M.A.; BREMNER, J.M. Use of p-nitrophenyl phosphate for assay of soil phosphatase activity. Soil Biology and Biochemistry, v.1, p.301-307, 1969.

TIESSEN, H.; STEWART, J.W.B.; COLE, C.V. Pathways of phosphorus transformations in soils of differing pedogenesis. Soil Science Society of American Journal, v.48, p.853-858, 1984.

TRASAR-CEPEDA, M.C.; GIL-SOTRES, F. Phosphatase activity in acid high organic matter soils in Galicia (NW Spain). Soil Biology and Biochemistry, v.19, p.281-287, 1987.

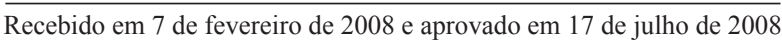

